\title{
Mysteriöse Wirkstoff-Pfade in den Körper
}

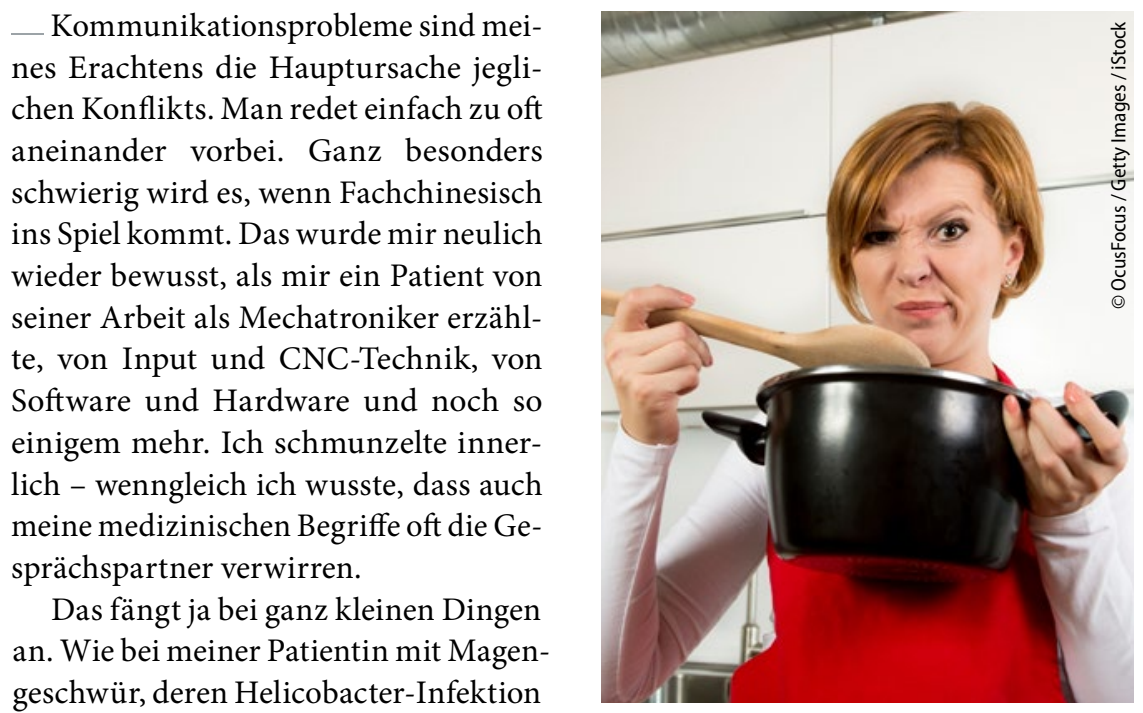
nur mit einer Tripletherapie beizukommen war, wenn sie nicht später an Krebs erkranken wollte. Das bedeutete drei Tabletten morgens, drei Tabletten abends, und das Ganze sieben Tage lang. Ich erklärte ihr ausführlich die Notwendigkeit dieser oralen Therapie. Sie schien aber unsicher - und fragte schließlich nur: "Wo hinein, Frau Doktor?"

Ich erkannte den Patzer: Sie hatte das Wort nicht verstanden. So beeilte ich mich, es mit ,in den Mund und mit Flüs- sitorium“ ist ein kompliziertes Wort. Einer meiner Patienten orientierte sich einfach an der Abkürzung und kochte das Medikament als Suppe!

Andere Patienten haben das Supp. dagegen in Tee aufgelöst, da es doch gar zu groß sei, um es zu schlucken. Mir zeigt das, dass ich kommunikativ stets auf der Hut sein muss.

Dr. Benita Martin, Chemnitz

\section{Nicht bestellte Nachrichten aus den unteren Regionen}

Es überrascht mich immer wieder, welch intime Dinge dem Hausarzt anvertraut werden. Ein etwa 50-jähriger Patient äußerte eines Tages den Wunsch, ich möge ihn bitte rektal untersuchen, ob er wohl etwas eng gebaut sei. Da sich hinter entsprechenden Beschwerden von der Hämorrhoide bis zum Karzinom so einiges verbergen kann, führte ich die Untersuchung durch. Unauffälliger Befund. Darauf der Patient: „Ach, dann bin ich beruhigt. Vermutlich ist der Dildo zu groß, den ich und mein Freund benutzen."

Dr. Henrich Malz, Vlotho

\section{Hier steht eine Anzeige.}

